\title{
Research on the Teaching Reform of Chinese Ancient Literature in Chinese Colleges and Universities
}

\author{
Chunxia LI \\ College of Chinese Language and Literature \\ Xi'an International Studies University \\ Xi'an, China
}

\begin{abstract}
This paper mainly discusses the problems and innovative measures in the teaching process of Chinese Ancient Literature in Chinese universities. Under the background of constantly updating and changing educational concepts and modes, the teaching of Chinese Ancient Literature in Chinese colleges and universities has exposed more and more problems, such as boring content, single teaching method and so on. To solve the problems above and gain a better teaching result, we should improve teachers' academic literacy, update teaching concepts, diversify teaching methods, strengthen teaching interaction and change teaching mode. Though the above efforts, we look forward to achieving better teaching results.
\end{abstract}

Keywords-Chinese Ancient Literature; curriculum content; teaching method; reform

\section{INTRODUCTION}

Chinese Ancient Literature has always been a compulsory basic professional course for Chinese Language major in colleges and universities in China, and its teaching level and teaching effect directly determine the quality of talent training for the whole Chinese Language major.

However, it has been a hundred years since Chinese Ancient Literature textbooks were published and used. In the new century, educational concepts are constantly updated, teaching methods are radically changing and teaching means are prodigiously diversified, which makes the teaching of the Chinese Ancient Literature in a dilemma. For example, such as obviously conservative teaching content, single and dull teaching methods and modes, gradually decline of teaching effect. Therefore, whether we are to promote the excellent Chinese culture or to promote the literary appeal and artistic aesthetic ability of Chinese Language major in colleges and universities, it is necessary to reform the teaching of Chinese Ancient Literature in Chinese colleges and universities.[1]

The time-honored cultural traditions of the Chinese nation need to be inherited and developed there is a close relationship between the design of Chinese Ancient literature curriculum and the revitalization of "GuoXue". Moreover, this course is directly related to the improvement of students' quality of traditional Chinese studies It is necessary for us to reform its teaching, In the course of curriculum reform, we should combine theory with practice to make this course serve students and society better. In view of the main problems existing in the teaching of Chinese Ancient Literature, this paper carries out the reform from its curriculum content and teaching method.

\section{IMPROVING THE ACADEMIC LITERACY OF TEACHERS AND PROMOTING TEACHING BY RESEARCH}

In terms of improving the academic literacy of teachers and promoting teaching by research, this is mainly the necessary measures taken to solve the problems of slightly outdated curriculum content and low interest of students in the classroom in the teaching process of Chinese Ancient Literature.

The method of promoting teaching by research is also called research teaching, which originates from the new educational ideas of Europe and America. In the 19th century, German educator Humboldt put forward the idea that university teaching should be combined with research. In the 1970s, facing the problems in higher education, the United States put forward a way of combining teaching and research to deal with them, that is, to advocate research teaching. In 1998, an academic report entitled "Reconstructing Undergraduate Education - Blueprint for American Research Universities" took the lead in pointing out that "a research-based teaching model should be established".[2] It can be seen that research teaching has become a new teaching concept which is concerned by Europe and the United States, and this concept is also suitable for the teaching of Chinese Ancient Literature.

Since the 1980s, in terms of the content of Chinese Ancient Literature is gradually broadened to cover Chinese history many aspects, and these aspects with each age, literature development develop the process of connection, broaden students' horizons. The relationship between study and history, literature and life has been recognized more deeply knowledge. In terms of literature itself, the course goes beyond poetry and prose, it also gives consideration to a variety of styles, including $\mathrm{Ci} \mathrm{Fu}$, parallel prose, novels, traditional Chinese opera and minority literature, which vastly enriched Chinese traditional literature. connotation and extension of learning. In addition, Chinese Ancient Literature also serves as cultural quality courses, humanities courses and international cultural education courses for domestic science and engineering 
students and foreign students functions and values are constantly expanding.

The influential textbooks of Chinese Ancient Literature mainly include the textbook edited by You Guo-en of Peking University in the 1980s, which emphasizes the class struggle as the center and lay particular emphasis on the popularity and class nature of literature; the Chinese Ancient Literature textbook edited by Guo Yu-heng of Beijing Normal University, which is characterized by clear entries and plain views; in addition, Chinese Ancient Literature textbook written by Luo Yu-ming of Fudan University, which focuses on human factors and emphasizes the relationship between human nature and Literature at the beginning of this century[3]. The Ancient Chinese Literature textbook edited by Yuan Xing-pei of Peking University is the most popular at the present, which emphasizes academic and advocates observing the law of development and evolution of Literature in different periods from the perspective of historical development and the evolution of literary. ${ }^{[4]}$ Each kind of the textbook has their own characteristics and utility, but their content presents certain stylized and routinized characteristics, and some of the contents of the textbooks are not comprehensive on academic trends and academic frontiers. Therefore, first of all, it is necessary to enhance teachers' academic literacy to improve their research ability, so that they can pay more attention to their own research field and grasp the academic frontier in addition to teaching. In addition, teachers can tell their mature academic concepts to students when they teach in order to introduce the latest research findings in the professional field for students. In this way, it can not only make up for the lack of attention paid to the academic frontier in the content of Literature textbooks, but also broaden students' horizons and boundaries.of understanding the content of Literature.

Moreover, the method of promoting teaching by research is decided by the nature of teachers in colleges and universities. The identity characteristics of teachers in colleges and universities require them to continuously improve their academic level. As the teachers in colleges and universities, they are different from middle school teachers in that they need to preach, teach and solve puzzles, they should not only follow the textbook, but have their own independent judgment on academic and be able to express new opinions which are different from the textbooks.

In addition, as far as the teachers in colleges and universities are concerned, this is not only the embodiment of their academic literacy, but also conducive to the cultivation of students' problem consciousness. Imagine that if the academic literacy of the teachers is very low, academic ability is general, so it is conceivable the effect of this kind of teaching. Teachers just follow the textbook on the platform, and the students fall asleep below, the teaching result must be very poor. Therefore, teachers should be good at finding problems, regard lifelong learning as their career that they need to practice all their lives, consciously pay attention to academic trends, and reasonably use academic theoretical achievements at home and abroad on the basis of consulting a large number of documents to draw objective and convincing conclusions. Moreover, teachers should continue the spirit of questioning tradition, being good at developing problems and solving problems on their own initiative in order to enhance students' awareness of problems and interest in learning.

From my years of teaching experience, I have always believed that teachers with high scientific research ability are more attractive in teaching, more able to infect students with their academic character, easier to stimulate students' interest in learning and exploring the course content, and easier to make students achieve better learning results.

Teachers who have their own academic view Through constant learning. may easier to gain students' recognition and respect, and for teachers themselves, They are also more likely to gain self-confidence and satisfaction. Under the interaction of the two, good teaching effect is easier to obtain.

\section{TAKING DIVERSIFIED TEACHING METHODS IN LIGHT OF ACTUAL SITUATION}

The extensive use of teaching methods, including multimedia, display pictures, play music and so on in the classroom. The teaching methods of Chinese Ancient Literature change quietly. Teachers can use the convenience of multimedia in teaching according to their actual needs. However, due to the unique subject nature of the Chinese Ancient Literature curriculum, the PPT can not be overused.

It must be admitted that the extensive application of PPT in the teaching has indeed provided a lot of convenience for some aspects of the teaching of Chinese Ancient Literature. Because the content of Chinese Ancient Literature is very complicated, if so many documents are written only by chalk, it will take up more teaching time, and through PPT text display, students can clearly and intuitively understand the content of works and the related documentation, which can really save a lot of blackboard-writing time and greatly improves the efficiency of teaching.[5] Moreover, the presentation of PPT content such as audio, pictures, video and so on can not only make students have intuitive and vivid feelings, but also make the classroom atmosphere lively. For example, when the teachers teach the Ming Dynasty opera "Peony Pavilion", they can start explaining it in the form of playing Kunqu Opera to let the students be inspired by the artistic beauty first, and then analyze the text, so that students can be motivated by subjective initiative through perceptual knowledge and then rise to the rational analysis of the text. This teaching method conforms to the general rule that people accept things with a step-by-step approach.

However, the particularity of the course of Chinese Ancient Literature determines that the use of PPT by teachers in teaching is limited. Because Chinese Ancient Literature has the characteristics of exploring people's hearts and emotions, and its curriculum content is the concentration of excellent traditional Chinese culture. One of the important purposes of this curriculum is to cultivate students' ability to understand and inherit excellent culture. Therefore, teachers must give students a clear explanation of the power of thriving and moving in the works, excavate the excellent national spirit contained in the works, implement the teaching concept of "all history is contemporary history and all contemporary history is history", and make the past a new one in teaching. However, it is well known that it is not easy to understand works, and we 
need to mobilize the dual ability of feeling and imagination. Teachers must accurately convey their understanding and perception of works to students through their academic literacy and life experience, so as to arouse students' resonance. However, it is impossible to accurately convey the power of "thriving" in works only by showing PPT.

Therefore, in view of the special nature of the Chinese Ancient Literature, teachers should use various teaching methods in the class, such as PPT, on the basis of actual needs, with the mission of inheriting excellent culture, rather than relying excessively on multimedia teaching.

\section{UPDATING TEACHING CONCEPTS, STRENGTHENING TEACHING INTERACTION BETWEEN TEACHERS AND STUDENTS}

The teaching concept is the ideological guidance for teachers to implement the teaching. Successful demonstration of a course must be the result of scientific teaching concept playing a certain role. As for the problems of fewer teaching class hours and insufficient interaction between teachers and students in Chinese Ancient Literature, this paper argues that teachers should be required to renew their teaching concepts and strengthen the interaction between teachers and students.

As the teaching reform is continuing in recent years, the teaching hours of Chinese Ancient Literature in colleges and universities have shown a decreasing trend, which has brought great pressure to teachers' teaching. As we all know, the teaching content of Chinese Ancient Literature is arduous due to its long systematic and complete characteristics. Therefore, it is impossible for teachers to be able to do everything in teaching when they are faced with the fact that teaching class hours are constantly decreasing. However, teachers also need to ensure that literary phenomena, literary schools and literary works in each period are sorted out clearly in limited class hours, which requires teachers to update their teaching concepts. In the specific teaching process, first of all, teachers should explain clearly the relevant general content framework in a specific historical stage. Then, teachers should take classical works as a foothold and analyze them one by one in several parts. Teachers should analyze and sort out the internal principles and external related factors of the occurrence and evolution of literary style in a specific historical period on the basis of explaining classical works. This kind of practice can not only achieve the far-reaching purpose of propagating the Chinese traditional excellent culture, but also reduce the possibility of teachers making superficial comments in the course due to the reduction of class hours. The specific approach is as follows.

\section{A. Concentrating on the main points}

For example, we can first summarize the background and literary style when we explain Jian'an Literature, then, we should take "San Cao" ,"Qi Zi" and Cai - Wenji as the core writers and objects of concern to analyze and discuss their classical works. Finally, we should analyze and demonstrate the rich connotation of "Jian'an Literature" by combing the content and style of their works.

\section{B. Diversified after-class tutoring modes}

Moreover, teachers can take a variety of ways to extend the limited classroom teaching to the outside of the classroom. For example, on one hand, teachers can make students read after class by arranging preview materials to enhance their familiarity with classroom teaching content.

(1) Teachers can give students timely feedback on their knowledge by assigning homework at the end of each week or a certain stage of the course. The form of homework should be flexible and varied, which can be understanding a literary school, the interpretation of the works of writers who are interested in, or their own creation of literary works.

(2) Organize group discussions after class. For example, Combine reading with writing, to structure ancient poetry into modern poetry with similar artistic conception

\section{Changing the dominant position of teaching and learning [6]}

According to the existing problems, we mainly discuss the following three aspects

(1) When we show the characteristics of the relationship between teachers and students, we usually use specific vocabularies such as "tutor", "lecturer", "professor" and "student" in a higher education environment, which indicates that there are unequal differences in knowledge mastery between teachers and students. Teachers should strengthen the frequency of interaction between teachers and students in teaching.

(2) To change their subject status between teaching and learning, both teachers and students should be regarded as the main body of teaching. The educational situation is a kind of interpersonal interaction-interpersonal communication. The key is to shift from a knowledge-based approach to a student development based approach. If we want to achieve this change, we must change the original "authority-dependence"[7] relationship between teachers and students, and establish a new type of "everything is done for students, do it for the everything about students", which is the new equal relationship between teachers and students.

(3) Students' learning and understanding should be regarded as guarantees in any effective teaching. Therefore, the two situations of imperative teaching relationship and passive absorption of knowledge can no longer exist in the field of higher education.

Because of the fewer class hours in Chinese Ancient Literature, the teaching method of "cramming education" has been adopted by most teachers in teaching. Although this mean is an effective way of disseminating knowledge, it is not only not conducive to training students' ability to think independently, but also will bring about the result that students' ability to take exams is improved and their ability to solve practical problems is reduced.

Therefore, teachers must renew their teaching concepts, strengthen the interaction between teachers and students, and adopt heuristic teaching methods in teaching, which requires the teacher to tell students their insights in the tone of "is this 
right? is this?” or to offer different opinions for students to discuss, encourage students to make their own evaluation of things, form their own views and give a clear demonstration process. It is the unshakable responsibility for modern college educational workers.

The mode of interaction between teachers and students can be flexible and diversified in the face of fewer class hours. For example, teachers can hold regular topic discussion groups after class, which can arrange several topics ahead of time, in the form of one person completing and team participation in a joint discussion. Another way is to carry out reading clubs, which should be divided into several periods according to the semester time and select the discussion content at each stage to participate in after-class reading and learning in the form of a team. Interactive communication between teachers and students will not only enhance teachers' understanding of students' characteristics and abilities but also form brainstorming and new research perspectives. The interaction and promotion between teaching and learning are beneficial to both teachers and students.

\section{CONCLUSION}

The teaching of Chinese Ancient Literature has gone through a century and accumulated rich experience, at the same time, we must admit that many problems have arisen under the new educational concept. Therefore, it requires us to combine the characteristics of the Chinese Ancient Literature to constantly reform the content and mode of curriculum learning; for example, we should improve teachers' academic ability,
Change the teaching subject, adopt various teaching methods and update teaching concepts.

Through the reform of teachers' teaching accomplishment, teaching concept and teaching method, we look forward to stimulating students' interest in learning Chinese excellent culture, enhancing students' learning efficiency. We make sure the reform measures above will greatly improve the teaching effect of the course of Chinese Ancient Literature, so as to make this course become an attractive basic course for Chinese Language major.

\section{REFERENCES}

[1] Liu Bao-cun, "Progress, Problems and Trends of Undergraduate Education Reconstruction in American Research Universities”, Studies In Foreign Education, 2004 (6) pp. 53-55

[2] Gao Yong-jun, Shi Zhou and Zhao Hong-ting, "Brief Talk on the Proposal and Practice of Research Teaching Model”, The Guide of Science and Education, 2010 (9)

[3] Zhang Pei-heng, Luo Yu-ming, "Chinese Ancient Literature”, Fudan University Press, 1997. pp.8-12

[4] Yuan Xing-pei, “Chinese Ancient Literature”, Higher Education Press, 1999. pp.11-21

[5] (England) Written by Ronald Barnett, “Translated by Lan Jinsong, The Idea of Higher Education”, Peking University Press, 2012. pp. 223-224.

[6] .He Xu-ming, "Interpersonal Relations in Teaching”, Journal of Higher Education, 2001 (1).

[7] Wang-Xia, "Research in Research-based Teaching in Universities, " Research in Education Development, 2007(11) 